\title{
Investigating a Japanese Authenticity-Blurring Mechanism in Discourse: "It's the Mood which has the Last Say in Our Discussion."
}

\author{
Hideki Hamamoto ${ }^{1}$ \\ ${ }^{1}$ Graduate School of Interdisciplinary Human Studies, Kindai, Osaka Japan \\ Correspondence: Hideki Hamamoto, Graduate School of Interdisciplinary Human Studies, Kindai, Osaka Japan. \\ Tel: 06-7493-9752. E-mail: hidekihamamoto@intl.kindai.ac.jp
}

Received: November 19, 2016

Accepted: January 3, 2017

Online Published: February 28, 2017

doi:10.5539/ach.v9n1p40

URL: http://dx.doi.org/10.5539/ach.v9n1p40

\begin{abstract}
Every culture has its own repertoire of characteristic discourse patterns. In a discourse, authenticity, which is related to socio-pragmatic strategies, is also culturally influenced. As is often noted, Japanese discourse patterns deviate from the Western norm in that the source of the influential view is intentionally blurred so that it is not easily traceable to its asserters. When the decision process is criticized, people concerned can say, "the mood had the last say in our discussion." This discourse pattern is referred to as atmospheric dominance. The purpose of this research is to identify sources of the phenomenon through philological research, citing data from the SeventeenArticle Constitution (compiled in 604), Manyousyu (the $8^{\text {th }}$ century anthology of poetry), Kojiki (the oldest chronicle, compiled around the $8^{\text {th }}$ century), and Nihon Shoki (the second oldest chronicle, completed approximately $8^{\text {th }}$ century). Our main point is that the concepts of $W a$ (harmony) and kotodama (language spirits) pertain to and constitute atmospheric dominance, which are defined with semantic metalanguage. This research clarifies how these two concepts are intertwined and work behind atmospheric dominance by citing documentaries, monologues, and newspaper articles, including the delay of publication of the meltdown incident in 2011.
\end{abstract}

Keywords: authenticity-blurring mechanism, atmospheric dominance, kotodama(言霊), $W a$ (和)

\section{Introduction - Authenticity-Blurring in Consensus-Forming}

The objective of this section is twofold: first, to clarify the importance of authenticity in serious discourse and the Japanese deviation from this norm; second, relating to this deviation, to identify some cultural sources pertaining to this particular pattern prevailing in Japanese discourse.

\subsection{Authenticity in Serious Discourse and Its Antonyms}

The definition of the word authenticity is given as the quality of being genuine, real or true. To be more specific, being authentic means the object concerned is as follows:

(1) a. genuine, real, of undisputed origin

b. made or done in the traditional, original way

c. based on facts, accurate or reliable

And its antonyms are as follows:

(2) a. not genuine, not based on facts, unreal

b. inaccurate, unreliable,

The process of consensus- forming in a group, can be characterized by four conditions:

(i) the decision process and the compromising process before reaching a conclusion are clearly recognizable to each participant,

(ii) the authenticity of a statement increases as the amount of supporting data accumulates,

(iii) the source of an influential view is traceable to its asserter, and

(iv) each participant recognizes his or her own role in consensus- forming. 
In daily life, however, being true to one's own personality or beliefs is not easily maintainable because we unavoidably live under the influence of social, moral and cultural pressures. Those external pressures are sometimes explicit and at other times implicit, particularly when they are deeply embedded in culture. People often conform their actions and judgments to external standards, such as the social pressure to adopt a certain social stance or value, and other institutional constraints.

Although we must admit the difficulty of being authentic under the influence of external pressure in daily life, the rules of authenticity in our discourse need to be obeyed when confronting critical problems, however difficult doing so might be. To give an extreme example, if your decision concerns a serious issue such as "whether to start a war," you need to return to the authenticity of consensus-forming, which is composed of the four terms; otherwise you will be accused of not following the due process of decision-making. At each step you follow in your discussion, you have to be attentive to what you and others say, and every utterance has to be clearly and officially documented in written form. Authenticity is a necessity for serious discourse.

Having acknowledged the importance of authenticity in formal discourses in both written and spoken forms to address serious topics, you may be astounded to learn how gravely some important Japanese discourses betray expectations of authenticity. Japanese discourse patterns sometimes deviate from the norm in that the source of the influential view is intentionally blurred so that it is not easily traceable to its asserters. Moreover, an allusion from a hierarchically higher person can influence others without that person a reason for his or her opinion. When the decision process is criticized, people concerned can say, "it is the mood which had the last say in our discussion." This prevailing discourse pattern is referred to as Kuki Shihai (空気支配, atmosphere dominance, kuki literally means air, Yamamoto 1983). This atmospheric dominance is clearly defined in the following way:

(3) In a discourse in which atmospheric dominance prevails, a statement may be any of the following:

a. not based on true, genuine judgements or emotion

b. not based on facts

c. not traceable to its asserters

These characteristics of atmospheric dominance are almost perfectly matched with the antonyms of authenticity in (2).

\subsection{Identification of Sources of the Authenticity-Blurring Mechanism}

We will consider some cultural concepts pertaining to the authenticity-blurring process. These important notions are $\mathrm{Wa}$ (harmony) and kotodama (spirits of words).

\subsection{1 $\mathrm{Wa}$ (和)}

We will start with the Japanese word $W a$, which is often translated as "harmony" in English. However, both $W a$ and harmony are culturally dependent. From the perspective of Cross-Cultural Pragmatics, Wierzbicka (1991:6) says, "to compare meanings expressed in different languages and different cultures, one needs a semantic metalanguage which is independent of any particular language or culture." We will see the comparison between $W a$ and harmony below soon, but before that, we need to clarify specific properties of the Japanese word $W a$.

When Japanese people hear the word $\mathrm{Wa}$ or "harmony," we almost automatically remember a historic figure of great wisdom. This person is Prince Shotoku (聖徳太子), who was a capable regent, diplomat and scholar. He compiled our country's first constitution in 604, i.e., the Seventeen-Article Constitution (十七条憲法), which, as William Theodore de Bary (2002) indicates, "placed more emphasis on basic moral and spiritual values than on the detailed codification of laws and their enforcement."

Since Shotoku's constitution talked about the importance of harmonious and logical discussion in plain language that everybody could understand, many people still argue that those aspects of discussion, not contradicted by any subsequent legislation, remain valid even today. However, some historians doubt whether the constitution itself was compiled so early by Prince Shotoku alone and even whether the Prince himself existed.

Shelving those doubts for a while, we must listen to his words of wisdom. Here, we see the first article and the seventeenth article pertaining to our present issue.

(4) The Seventeen-Article Constitution(十七条憲法)

(i) The first article

Harmony should be highly valued and quarrels should be definitely avoided. Everyone tends toward forming a clique. However, wise and reasonable people are in a minority. Therefore, some disobey their superiors and 
fathers, and others argue with their neighbors. If superiors are calm and subordinates are reasonable in discussing matters, every discussion will be accord with reason, which brings everything to its completion.

(ii) The seventeenth article

Making an important decision, you must discuss with others. You may decide small matters alone. However, important issues need to be discussed with others to avoid an error. If you discuss with others, you will obtain a reasonable conclusion.

As you can see, the first article talks about the importance of harmony in discussion to avoid conflicts, and the seventeenth article urges people to discuss any issues with others for a reasonable conclusion. However, people, at present, are prone to emphasize the significance of the first article and pay little respect to the seventeenth article. They think that they should maintain harmony with others in discussion all the time, which leads to $W a$ 's cultural heterogeneity.

Consider now the difference between the common Japanese concept $W a$ and harmony in English. Patricia Clancy notes the following:

The Japanese reliance upon indirection is consistent with their attitude towards verbal conflict. As Barnland points out, in Japan a conversation is a way of creating and reinforcing the emotional ties that bind people together with the aim of social harmony. And overt expression of conflicting opinions is taboo. Even conference participants tend to express their views tentatively, in anticipation of possible retraction or qualification depending upon how they are received. They try to feel out the positions of their colleagues, seeking a common ground for establishing unanimity. [...] Individuals may hold their own view, but, in the interests of group harmony, should not express it if it conflicts with the opinion of others. (Clancy 1986:215)

Considering this comment, Wierzbicka (1991) provides the definition of Japanese "harmony" and its Western counterpart in the following:

(5) Definition of Japanese $W a$ and Anglo-American 'harmony' in the semantic metalanguage (Wierzbicka 1991: 114)

\section{(i) Japanese $W a$}

When someone says something

I can't say: 'I don't think the same'

Someone could feel something bad because of this

When people say: 'we all think the same.' It is good

(ii) Anglo-American 'Harmony'

I can say what I think

You can say what you think

We don't have to think the same

This is good: no one has to feel something bad because of this

The main difference between the two concepts is that $W a$ emphasizes being the same with others in thought, while harmony allows for differences in thought. In (5i), "we all think the same. It is good." This acute observation clearly indicates our interpretation of harmony; that is, Japanese people prefer to be the same as others rather than to be argumentative in a discourse and to our regret, ignore the spirt of Prince Shotoku's seventeenth article. However, we need to admit that trying to pursue like-mindedness with others will work very effectively as long as a group is working for some positive goal that is transparent to public eyes, as in competing with a rival in a sport or business situation. The problem surfaces when people place the priority on being accordant with others within a group, and place connivance at others' malpractice out of the public eye. Here, we hasten to add another cultural heterogeneity, which is that Japanese people tend to make a sharp distinction between $u c h i$ (内 the ingroup) and soto (外 the out-group). Uchi literally means a home, but its meaning can be extended to refer to a company or a section to which one belongs. People's attitude of like-mindedness reflects this distinction. While having the same mind and sentiment with others in a group is strongly required, being indifferent to and nonchalant about the out-group is permissible, even when a serious issue is addressed.

Although Wierzbicka's indication about Japanese $W a$ is much to the point, her idea covers mainly the status quo of the socio-linguistic understanding of the term. Our ancestors had a high affinity with the intrinsic and original 
interpretation of $\mathrm{Wa}$, that people should discuss any issues logically to avoid an error, while having in mind the importance of harmony in discussion to avoid conflicts. Our ancestors seem to have taken more liberty in expressing their beliefs without caring much about the similarity of their remarks to those of other members. ${ }^{1}$ As an example of the freedom of expression that the older generation used to have, consider the following poem by Akiko Yosano(1904,与謝野晶子, English translation by Binard, A (2007)): ${ }^{2}$

I cry for you, Brother.

don't you dare lay down your life

you, the youngest child in our family,

thus cherished all the more-

Mother and Father didn't educate you

to wield weapons and to murder; they didn't

bring you up, to the age of twenty-four,

so that you could kill, or be killed yourself

You were born into a long line

of proud tradespeople in the city of Sakai;

having inherited their good name,

don't you dare lay down your life,

What does it matter if that fortress

on the Liaotung Peninsula falls or not?

It's nothing to you, a tradesman

with a tradition to uphold.

Don't you dare lay down your life

The Emperor himself doesn't go

to fight at the front; others

spill out their blood there.

If His Majesty be indeed just

and magnanimous, surely he won't wish

his subject to die like beasts.

nor would he call such barbarity "glory." [...]

This ballad, even stating that the Emperor himself does not go to fight at the front, expressed the author's antiwar sentiment in an unreserved way and appealed to the readers ardently.

We will see many cases of atmospheric dominance where negative aspects of $W a$ operate on decision-making within a group in section 2. Before talking about these cases, we will look at another important cultural factor which contributes to producing non-authentic, obscuring statements.

\subsubsection{Kotodama (言霊)}

An unfamiliar but important and deep-rooted concept is Kotodama, which literally means "spirits of words" (the mystical power believed to dwell in words). In ancient times, events (事, pronounced "koto") and words (言, pronounced "koto") were thought to be identical (Toyota 1980), in the sense that saying good words invited good things and saying bad words attracted something evil. Mutual dependence of this type is close to the notion of Fraser's sympathetic magic. Fraser (1922) classifies magical thoughts into two types:

IF we analyze the principles of thought on which magic is based, they will probably be found to resolve themselves into two: first, that like produces like, or that an effect resembles its cause; and, second, that things which have once been in contact with each other continue to act on each other at a distance after the physical contact has been severed. The former principle may be called the Law of Similarity, the latter the Law of Contact or Contagion. From the first of these principles, namely the Law of Similarity, the magician infers that he can produce any effect he desires merely by imitating it: from the second he infers that whatever he does to a material object will affect equally the person with whom the object was once in contact, whether it formed part of his body or not. Charms based on the Law of Similarity may be called Homoeopathic or Imitative Magic. Charms based on the Law of Contact or Contagion may be called Contagious Magic. (Fraser 1922, vol. I: 52)

We will see some examples from Manyousyu (万葉集, the old anthology of Japanese poetry), Nihon Shoki (日本書紀, the second oldest chronicle completed around the $8^{\text {th }}$ century) ${ }^{3}$ and Kojiki (古事記, the oldest chronicle compiled around the $8^{\text {th }}$ century). ${ }^{4}$ Manyoush $u$, which literally means the collection of ten thousand leaves, is the 
$8^{\text {th }}$ century anthology of Japanese poetry. It has only eight entries of poetry that include the word kotodama, but many pieces of poetry more or less relate to its magical power. These are some pieces of poetry from Manyousyu (6a-c) and from Nihon Shoki (6d), all of which are related to spirits of words.

(6) Some examples of poetry pertaining to spirits of words

a. Yamato, with Shrine at Shikishima, is a land

blessed with the spirit of words,

happiness prevails.

(Manyousyu, vol.13, 3254, Kakinomoto Hitomaro)

b. Looking back on the fields of heaven,

His Majesty's life spreading long, broad

fills the heaven.

(Manyousyu, vol.2, 147, Empress Yamato)

c. Today, at the beginning of a New Year, New Spring,

snow piles up, good and happiness also adds up.

(Manyousyu, vol.20, 4516, Otomo Yakamochi)

Erecting the beautiful pillars makes the lord peaceful,

Setting the strong beams, girders makes the lord prosperous,

Preparing the rafter beautifully makes the lord settled,

Arranging the straw-thatched roof strong and fast makes the lord at ease, [...]

(Nihon Shoki, vol.15)

The first poem (6a) describes how this country is blessed with spirits of words. Example (6b) is a poem written by Empress Yamato (大和皇后) wishing for the Emperor Tenchi's (天智天皇) recovery from a serious illness. She describes it as a fact that the emperor's life is strong enough to fill the heaven. This is a typical example of the belief that good words invite a good state. The third example (6c) is read on a new year's day to invite happiness to add up as the snow piles up. The last example (6d) is read aloud not only to celebrate a new house but also to predestine happiness and the health of the lord of the house. This last one reminds us of Fraser's previously mentioned contagious magic, in which praising a material object belonging to a person will affect the person equally favorably. As Philippi (1990) says, "The ancient Japanese delighted in the pronouncing of 'blessings' designed to ensure longevity and prosperity by referring adroitly to, for instance, the abundance of the grass thatched on the roof or the firmness of the ropes tied in place around the beams."

The examples above are all written in the present tense but, strictly speaking, the utterances of congratulatory words do not have tense. Clear affirmation of a desirable state without reference to tense may move the spirits of words toward the situation they describe.

Saying something good invokes a good state. However, the reverse is also true. If one says something wrong or bad, that brings a bad state to him- or herself. As Naumann (1999) notes, "the sympathetic magic potential in the process of lifting up words had become so powerful that it was generally regarded as a technique too dangerous to employ except under the most extraordinary circumstances." See an example of this negative impact of kotodama on Yamato Takeru (a legendary worrior prince) from Kojiki (Record of Ancient Matters).

(7) Yamato Takeru(日本武尊), who blasphemed God of Mount Ibuki, was punished by the deity due to his lifting up of the wrong words:

Yamato Takeru said: "As for the Deity of this mountain, I will simply take him empty-handed." —and was ascending the mountain, when there met him on the mountain-side a white boar whose size was like that of a bull. Then he lifted up words, and said: "This is a messenger from the Deity. I will not kill it not now, I will kill it when I return,"- and ascended. But this was not the deity's messenger which had been transformed into the white boar, it was the deity himself, and the deity "caused a violent hailstorm and dazed Yamato Takeru—an illness that led to his death. (Kojiki, the Middle vol.)

Yamato Takeru was punished by the deity because of the lifting up of the wrong words. Although Yamato Takeru who incurred punishment was a tragic hero in the mythical world, people today are still very concerned about this 
negative effect of the kotodama. They prefer to be silent rather than to express an opinion that may be wrong and draw some misfortune upon them.

The Japanese language is full of homonyms. Before the introduction of Chinese characters into our writing system, words with the same sounds were naturally considered to have close mutual dependence. Those equivoques that share sounds were assumed to have sympathetic resonance psychologically based on Fraser's Law of Similarity. This sympathetic resonance contributes isomorphism between language and reality: what we describe with words will project onto how eventualities are formed in actuality. Kotodama, which sounds mystic and oracular, is actually based on this simple sympathetic resonance. Surprisingly, even today people try to avoid unpropitious words. They are particularly conscious about the selection of words on special occasions, like going to the hospital or attending a wedding ceremony. Consider example (8):

(8) Examples of kotodama constraints

a. There are no no. 4 rooms at any hospital. (=because shi (四, four) is pronounced exactly like death (死))

b. When you visit somebody in the hospital, you never bring a potted plant as a gift.

(=because a potted plant takes root and netsuke (根つく, taking root) has the same pronunciation as taking to one's bed, 寝付 <)

c. At wedding ceremonies we must not use words like modoru (戻る return) or owaru (終わる end).

(=because a happy marriage life should be long and forever)

d. When one finds a comb on the street, he or she will never pick it up because "comb" is pronounced as “kushi (櫛),” which exactly sounds the same as "pain and death (苦死).”

So both positive and negative functions of the kotodama are illustrated as in the following:

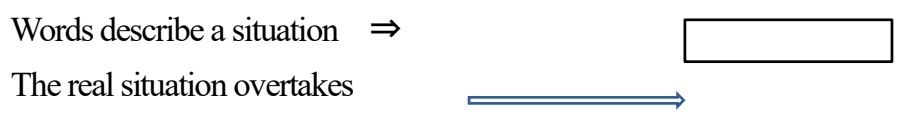

Figure 1. Using congratulatory / unpropitious words

These functions are also defined in semantic primitives as in (8):

(9) Functions of sprits of words

a. Definition of positive aspect of spirit of words.

If you say something good, things will go as you say.

b. Definition of negative aspect of spirit of words.

If you say something wrong or bad, things will go as you say.

From this step, it is easily conceivable how the mechanism of atmospheric dominance is synthesized: (i) As I mentioned above in (5i), the presently accepted version of the Japanese concept of $W a$ is defined as: "when someone says something, I can't say: I don't think the same. Someone could feel something bad because of this. When people say: we all think the same, it is good." So we should sound out what other members think to avoid conflicts and try to pretend to think the same as they do. (ii) Saying something wrong, inaccurate or sinister will draw negative effects toward a speaker as shown in (9b). (iii) Therefore, the best policy is that one should refrain from lifting up the words and follow the atmosphere of the situation. This is the background against which the atmospheric dominance is formed in a discourse. Assuming this cultural background, we can proceed to the mechanism of the atmospheric dominance defined as in (10):

(10) The mechanism of Atmospheric Dominance

(i) People are likely to keep silent rather than speak up because of the kotodama constraint.

(ii) People tend to seek for sameness and to avoid discord because of the $\mathrm{Wa}$ constraint.

(iii) Therefore, $\mathrm{X}$ can capitalize on these two sentiments to blur the authenticity in a discourse. (X in many cases cannot be identified) 
The above section summarizes how cultural factors compound the atmospheric dominance in a discourse. The following section outlines a number of concrete examples from various texts to corroborate the account of how this discourse-obscuring mechanism works.

\section{Evidence of the Atmospheric Dominance from Various Texts}

I will show some examples of the atmospheric dominance from newspaper articles, documentaries, and monologues, including the delay of publication of the meltdown incident in 2011.

\subsection{Documentary of Battleship Yamato}

The August 1975 issue of Bungeishunjyu (文囈春秋, a popular monthly magazine) features the attempted suicide attack of Battleship Yamato, which was the last offensive of the Imperial Navy, taking place in 1945. Yamato, a superdreadnought, remained undamaged toward the end of the Pacific War. In April 1945, the Naval General Staff decided to commit Yamato to the front by sending it in the direction of Okinawa without air cover. The director of the $2^{\text {nd }}$ fleet, Admiral Ito, who would be in charge of this mission, at first was not convinced by Chief of Staff Mikami, who was sent to persuade him to accept the mission as a messenger from the Naval General Staff. Here are some excerpts from Battleship Yamato (Bungeishunjyu 1975:233).

Admiral Ito: $\quad$ The fleet, having only enough fuel to arrive there but not return, and without air cover was nothing but a suicide attack. I firmly reject that nonsensical attack, which is a waste of our seamen.

Mikami: I must admit that, in any situation, sending the naked fleet into the open sea where the American task force is on watch will not take shape as a true operation.

Mikami cont'd: However, we sincerely want you to consider this. Acting in concert with the Army's allout attack, your fleet, as a shock unit, will land on Okinawa, after which all of your seamen will fight against the Americans as land troops.

On hearing this, Ito immediately understood the true message of the order. This unreasonable request was irrefutable since it reflected the mood of the Naval General Staff that Yamato, as the symbol of Imperial Navy, should die a glorious death. Yamato's survival of the war would have been assumed to be a disgrace to the Navy. Ito finally agreed: If that is so, what's left to say? I have granted your order.

We will make a sortie immediately after the preparation is ready.

After the war, one of the Naval General Staff members, Admiral Ozawa, recalled the time (Bungeishunjyu 1975:232):

Ozawa: Considering the general atmosphere, at that time and at present, I firmly believe the final sortie of Yamato is something that had to be done.

What Ozawa wants to claim is that the justifiable grounds for the final attack were not any strategic data but simply the atmosphere at the time. It is the atmosphere that has a final say, not necessarily reasonable data or rationality.

People involved in planning the final sortie were all Navy specialists, well acquainted with strategies, logistics and technical details, but they did not seem to follow the logically conceivable process of decision-making. In this respect, their decision-making was not authentic but dominated by the atmosphere. Those Naval General Staff members should have taken on the responsibility of specialists, making their decision by themselves using their expertise. That is, they all should have been more positively individualistic (not egotistical), dependent solely on their expertise and judgments, not being constrained by the atmosphere. They could not make decisions as individuals, instead going with the flow and taking no individual responsibility. The elite in the Navy seemed to be blindly obedient to the atmosphere and prone to say "It can't be helped." In this respect, obfuscation of the authenticity of individual opinions is strongly connected to irresponsibility. Their discourse pattern is formulated as in the following:

(i) (The Naval elite think that this operation is doomed to failure.) If they say this, this ominous event actualizes. They remain silent because of the kotodama constraint.

(ii) The atmosphere of the Naval General Staff is already decided. They think the same thing as is implied by the atmosphere because of the $\mathrm{Wa}$ constraint.

(iii) Therefore, they create a disguising operation that lands Yamato on the shore as battery. 


\subsection{The Emperor Showa's Monologue（昭和天皇独白録）}

In the context of the last war, there were many episodes that quite aptly revealed Japanese authenticity-blurring mechanisms. As a good illustration of this, we will look at the circumstances in which the Empire of Japan was involved in the decision to start the war, which is actually full of startling discoveries. To understand this, we need to discuss some historical and political facts. Under the institution of the Meiji Constitution, the administration was that of a constitutional monarchy, in which usual, day-to-day affairs in the government were managed by the cabinet system. The Emperor was stipulated as the head of state and the Prime Minister and the cabinet were considered advisors. This pre-war system was riddled with flaws. The first defect was the fact that the Prime Minister did not have the right to choose a minister. Therefore, if a member of the cabinet led a rebellion, the Prime Minister, having no right to replace him, had to dissolve the entire cabinet. This weakness was used by the Army as an effective threat to the cabinet to obtrude their opinions on other members. The second controversial issue about the system was that the supreme command of both the Navy and the Army directly belonged to the Emperor, and the cabinet was not in a position to interfere in military issues. However, the Emperor himself, being set up as the head of state, was expected to follow an unwritten commandment, i.e., he should consent to any proposed measures from both forces as well as from the Cabinet.

On critical matters of grave importance, "Imperial Conferences," which were extraconstitutional, were convened to obtain final imperial approval for courses of action. At those meetings, the Emperor listened to discussions, but remained silent. The following is an excerpt from The Emperor Showa's Monologue, discovered in 1990. Five chamberlains compiled the Emperor's monologue, tracing things he said from 1928 to 1945.

On the Imperial Conference

What has been referred to as the Imperial Conference is queer. Since all the attendees except the President of the Imperial Council have already agreed upon a bill at a Cabinet meeting or at a Liaison Conference, the only attendee who can object to it is the President of the Imperial Council. I am always vastly outnumbered, which leaves me nothing to do. This conference is purely formal and the Emperor does not inhere the power of decision over the atmosphere of the meeting. (Emperor Showa's Monologue 1990: 56)

On September 6, 1941, two months before the war, at the Imperial Conference, the Emperor, who was keen on giving priority to diplomatic negotiations before war preparation, breaking the tradition of Imperial silence, directly questioned the chiefs of the Army and Navy general staffs on this matter. None of them replied appropriately. Then, the Emperor stressed once again the need for peaceful resolution of the crisis and recited a poem written by his grandfather, Emperor Meiji:

The seas of the four directions

All are born of one womb,

Why do the wind and waves rise in discord!

(Emperor Showa's Monologue 1990: 76)

However, this was all that he was able to do. He was not able to change the atmosphere in which all of the speakers were already united in favor of war rather than peaceful negotiation. To our surprise, however, none of them had a clear strategy of how they would be able to conduct the war against the U.S., England, and the Netherlands to the state's victory. They all knew, as war specialists, Japan's war potential at that moment was just one-twentieth of that of the US alone. Their vague hope was that by giving to the US fleet at Pearl Harbor a quick knockout blow, which would stun American forces, they might be able to find a way through the turmoil.

The above stories, curtailing the details, may describe how Japanese prefer to avoid being argumentative in accordance with the logical procedure or authenticity necessarily involved in a decision-making process even when they need to decide important issues. Speakers always look for a point of compromise so as not to cause others to lose face and the best solution is not logical conclusion but harmonious agreement. In this case the following is how the atmospheric dominance functions:

(i) All the members of the imperial conference think that this war leads to failure. If they say this ominous words, what they describe actualizes. They remain silent because of the kotodama constraint.

(ii) The conference atmosphere was in favor of war. They need to think the same way as the conference atmosphere implies because of the Wa constraint.

(iii) (Even though everybody forebodes that this war ends with tragedy) they remain silent. ${ }^{5}$ 


\subsection{The Obfuscation of Authenticity in the Fukushima Nuclear Reactor Incident（福島原子力発電所事件）}

The obfuscation of authenticity and its related irresponsibility are not limited to wartime, but are still rampant in present-day Japan. The incident of the Fukushima Daiichi nuclear power plant will never fade from our memory. On March 11, 2011, the East Japan Disaster occurred (the earthquake and following tsunami). After the devastating earthquake, a large tsunami smashed the coastline and flooded the nuclear power plant at Fukushima. The largest tsunami wave was 13 meters high and hit 50 minutes after the initial earthquake, overwhelming the plant's seawall. The flood damaged the generators resulting in a loss of power to the coolant water pumps. These pumps must continuously circulate coolant water to keep the fuel rods from melting. After the secondary emergency pumps ran out, one day after the tsunami, 12 March, the water pumps stopped and the reactors began to overheat. The insufficient cooling eventually led to meltdowns in reactors 1,2 , and 3, where the fuel rods melted through the bottoms of their reactor pressure vessels. The manual of Tokyo Electric Power Company Holdings (TEPCO) clearly defines the threshold for which the term "meltdown" should be used, and the threshold had been already exceeded. However, on 14 March 2011, TEPCO officials were instructed not to use the ominous phrase "core meltdown" at press conferences. They might have believed that the ominous and inauspicious words would have fixed the situation as it was. This inhibition was said to be following an instruction from the government (of course, the person who instructed this is not clear). They kept using the much milder words "damages to the fuel." Strangely, this manual that clearly defines when to use the word "meltdown" disappeared (or was hidden?). TEPCO kept lying that there was no ground by which to judge when to use the term "meltdown." Eventually, in February, 2016 this manual was discovered:

Nikkei Shinbun (日本経済新聞Nikkei Newspaper) 22 June, 2016

TEPCO President Naomi Hirose apologized for his company's cover-up of using the word "core melt down." He said that it was revealed that Mr. Shimizu TEPCO president at that time instructed on 14 March 2011 not to describe the reactor damage using the word "meltdown." Officials at that time were aware that $25-55 \%$ of the fuel had been damaged, and the threshold for which the term 'meltdown' became an appropriate (5\%) had been greatly exceeded. told the media: "I would say it was a coverup... It's extremely regrettable." However, he remained silent to the question whether somebody at the Prime Minister's Official Residence pressured him or not.

Just as in the case of the Battleship Yamato, the people involved in this incident were all specialists, well acquainted with technical details, but did not follow the authentic process of decision-making. The negative impact of inauthenticity in a discourse rises to the surface when people place the priority on being accordant with others within a group. Japanese people are often said to make a sharp distinction between uchi (the in-group) and soto (the out-group). Uchi literally means a home, but it can be extended to refer to a company or a section one belongs to. Many people, not only because of the fear of being ostracized by airing a candid opinion but also because of the forging of a stronger comradeship, tend to have an obsession with the congruity of ideas within the uchi or ingroup. This invokes the authenticity-blurring behaviors, which in our recent history have sometimes led to committing irreparable mistakes. The atmospheric dominance in this incident can be depicted as follows:

(i) (Top executives know that the manual defines "melt down" ) If they use the ominous word "meltdown," it actualizes. They evade the word because of the kotodama constraint.

(ii) They think and act the same way as others within $u c h i$ (inside the company). They do not use the word because of the $\mathrm{Wa}$ constraint.

(iii) They keep using "damages to the fuel" instead of "core meltdown."

\subsection{The Toshiba Corp.－Accounting Scandal（東芝不正経理事件）}

Finally, we will turn to a recent scandal in one of the largest companies in Japan. Toshiba Corp., which produces everything from nuclear reactors to home appliances, is involved in a $\$ 1.2$ billion accounting scandal, which was caused by top executives setting unrealistic profit targets. Shall we read an excerpt from The Japan Times's Editorial?

Learning from the Toshiba Scandal (The Japan Times's Editorial 23 Jul, 2015)

[...] It's also not clear if Toshiba has come to grips with the problem. In a report released on Monday, an independent panel of lawyers tasked to probe the accounting irregularities concluded that inappropriate accounting practices went on for years "in a systematic manner" in many of its business divisions based on the "involvement of the top management." According to the panel, its probe of inhouse communications at the firm revealed that Toshiba had a "corporate culture" in which the employees were unable to go against the wishes of their superiors, and determined that its top executives 
— president H. T and his two predecessors, vice chairman N. S and adviser A.N — forced the division managers to engage in improper accounting to inflate the profits by adding strong pressures on them to meet the profit targets. The president $\mathrm{T}$, who apologized for the scandal in a news conference on Tuesday, still denied that he put pressure on the division managers to pad the profits, saying that he did not realize he was telling the managers to manipulate the accounting. [...]

It is reported that none of the top leaders of Toshiba told their managers to manipulate the accounting; but all they said was "challenge." However, these managers, who needed to show loyalty to the company, must not answer back but must remain silent for making a conjecture on what their bosses meant. The managers are required to think the same as their colleagues and infer what they should do to satisfy the executives who did not actually tell them the instruction verbally. This whole discourse pattern follows the formula of atmospheric dominance:

(i) (Many managers are suspicious about the company's financial status.) If they say this, the ominous situation actualizes and they will be punished. They remain silent because of the kotodama constraint.

(ii) (Top executives encourage them to challenge.) They need to obey this demand as a team inside the company because of the $\mathrm{Wa}$ constraint.

(iii) They manipulate the accounting.

This is another typical case in which the atmospheric dominance mechanism shown in (11) marvelously worked: (11=(10)) The Mechanism of Atmospheric Dominance

(a) People tend to seek for sameness and to avoid discord.

(b) People are likely to keep silent rather than speak up.

(c) Therefore, $\mathrm{X}$ can capitalize on these two sentiments to blur the authenticity in a discourse. (X in many cases cannot be identified.)

\section{Conclusion: Beyond the In-Group Congruity}

Observing various cases that testify to the authenticity-blurring, we need to admit that the atmospheric dominance is still rampant in Japanese culture. The concepts of $W a$ and the kotodama, both of which have cultural and historical grounds and constitute atmospheric dominance, extend strong socio- and psycholinguistic influence on the verbal and social behaviors of Japanese people. We are more concerned with is the fact that Japan's younger generation also seems to be very conscious about the atmospheric dominance. They often use a phrase that clearly relates to atmospheric dominance as in (12) below:

(12) (At an office a senior lectures a new recruit on an implicit rule)

意見を言う前にもっと空気を読め

Iken o i u maenimotto kuki o yome.

opinion (direct obj) say before more air (direct obj) read (imperative)

You should be more sensitive to the atmosphere before you say your opinion.

The phrase "kuki o yomu" literally means "read the air," and conveys that you should be more sensitive to the atmosphere you are in. Japanese organizations and social institutions require people's sensitivity to the atmosphere and to same-mindedness within a group. Pursuing like-mindedness within a group is not intrinsically wrong as far as a small issue is concerned. A group in which each member is opinionated about trifles may lose the chance to advance further. Therefore, a group whose members are like-minded may have an advantage to tackle a problem swiftly. However, once they need to address serious issues, they need to return to the basics of being authentic in a discourse. We need to remember that, unlike the presently accepted notion, the intrinsic and original idea of $W a$, which was shared by people until early twentieth century, allowed them to take the liberty of expressing what they believed without caring much about the congruity of an in-group. Therefore, we need now to retrieve the authenticity of our own opinions even in an in-group discourse, which in the short term may damage the rigid form of conformity of an in-group but in the long run may help to restore more natural transparency in a much broader perspective.

\section{References}

Binard, A. (2007). Nihon no Meishi Eigo de Odoru (Japanese poems dancing with English). Tokyo: Misuzu Shobo.

Brown, P., \& Levinson, S. C. (1987). Politeness. Cambridge: Cambridge University Press. 
Clancy, P. (1986). The acquisition of communicative style in Japanese. In B. B. Schieffelin, \& E. Ochs (Eds.), Language socialization across cultures (pp. 213-250). Cambridge: Cambridge University Press. http://dx.doi.org/10.1017/CBO9780511620898.011

de Bary, W. T. (Ed.). (2002). Sources of Japanese Tradition, Volume One: From Earliest Times to 1600 (2nd ed., vol. 1). Columbia University Press.

Fraser, G. J. (1913). The Magic Art and Evolution of Kings (Vol 1, 2 of The Golden Bough). London: Macmillan.

Fujimura, I. (2016). Toten Miyazaki and Sakuzo Yoshino: Thoughts on Asian Solidarity and Universalism in Prewar Japan. Asian Culture and History, 9(1). http://dx.doi.org/10.5539/ach.v9n1p1

Maynard, S. K. (1998). Principles of Japanese discourse. Cambridge University.

Philippi, D. L. (1990). Norito: a Translation of the Ancient Japanese Ritual Prayers. Princeton: Princeton University Press.

Sasaki N. (1991) Manyousyu (Vol. 1 \& 2).

Terasaki, H. (ed.) (1995). Showa Tenno Dokuhakuroku. Tokyo: Bungeisyunjyu.

Toyota, K. (1980). Nihonjin no Kotodama Shisou.

Tsugita, M. (1977). Kojiki (Vol. 1, 2, \& 3).

Tsujimura, A. (1987). Some characteristics of the Japanese Way of Communication. In D. L. Kincaid (Ed.), Communication Theory (115-126). Academic Press. http://dx.doi.org/10.1016/B978-0-12-4074750-5.50014-1

Ujitani, T. (1988). Nihonshoki (Vol. 1, 2, \&3).

Wierzbicka, A. (1991). Cross-culture pragmatics. Mouton DeGruyter.

Yamamoto, S. (1983). Kuki no Kenkyu (Study of Mood). Tokyo: Bungeisyunjyu.

Yosano, A. (1904). Kimi Shinitamou Kotonakare. Myojyo.

\section{Notes}

Note 1. Japanese people used to be more forthright in expressing themselves in public when necessary. This is apparent in the literature; for example, war chronicles (written from the end of the ancient times to the medieval period) such as Heike Monogatari (平家物語) and Taiheiki (太平記), in which Samurai worriers would express their views blatantly to protect their own honor. Seemingly, this attitude of making candid statement of their own lasted toward the end of Taisho Democracy (1905-1925) and, thereafter, weakened with the tide of militarism, after which Japan advanced the road to World War II.

Note 2. Written by Akiko Yosano (与謝野晶子), when her younger brother was conscripted and sent to the front in the Russo-Japanese War in 1904. This verse first appeared in Myojyo(明星). The English translation was done by Arthur Binard (2007).

Note3. Nihon Shoki (日本書紀, Chronicles of Japan) is the second oldest book of classical Japanese history, and it was divided into 30 volumes and compiled in the $8^{\text {th }}$ century. The chronicle begins with the Japanese creation myth. Example (6d) was composed by Emperor Kenzo. (Ujitani 1988: 321)

Note 4. Kojiki (古事記, Records of Ancient Matters) is the oldest extant chronicle, composed in the early 8th century. This is a collection of myths concerning the origin of Japan, which is divided into three parts: the first volume, the middle volume and lower volume. The episode of Yamato Takeru's death appears in the record of the Emperor Keiko. (cf. Tsugita 1980: 160)

Note 5. This decision of keeping silent reminds us of Don't do the FTA of Brown and Levinson (1987:69). Fundamental to their theory is the concept of face. However, the basic difference between their theory of face and the present theory is that their choice of silence is not to run the risk of losing the addressee's face, while my elucidation of keeping silent is focused not on the face of the addressee but on the congruity of the group concerned.

\section{Copyrights}

Copyright for this article is retained by the author(s), with first publication rights granted to the journal.

This is an open-access article distributed under the terms and conditions of the Creative Commons Attribution license (http://creativecommons.org/licenses/by/4.0/). 